OPEN ACCESS

Edited by:

Richard Sayre,

New Mexico Consortium at LoS

Alamos National Labs, USA

Reviewed by:

Antonio Ferrante,

Università degli Studi di Milano, Italy

Mohamed Hamed Arisha,

Zagazig University, Egypt

*Correspondence:

Zhen-Hui Gong

zhgong@nwsuaf.edu.cn

${ }^{\dagger}$ These authors have contributed equally to this work

Specialty section

This article was submitted to

Plant Biotechnology,

a section of the journal

Frontiers in Plant Science

Received: 18 May 2015

Accepted: 28 September 2015

Published: 13 October 2015

Citation:

Wang S-B, Tian S-L, Shah SNM,

Pan B-G, Diao W-P and Gong Z-H (2015) Cloning and characterization of the CarbcL gene related to chlorophyll

in pepper (Capsicum annuum L.)

under fruit shade stress.

Front. Plant Sci. 6:850

doi: $10.3389 /$ fpls.2015.00850

\section{Cloning and characterization of the CarbcL gene related to chlorophyll in pepper (Capsicum annuum L.) under fruit shade stress}

\author{
Shu-Bin Wang ${ }^{1 \dagger}$, Shi-Lin Tian ${ }^{2,3+}$, Syed N. M. Shah ${ }^{2,4}$, Bao-Gui Pan ${ }^{1}$, Wei-Ping Diao ${ }^{1}$ and \\ Zhen-Hui Gong ${ }^{2 *}$ \\ 1 Institute of Vegetable Crops, Jiangsu Academy of Agricultural Sciences, Nanjing, China, ${ }^{2}$ College of Horticulture, Northwest \\ A\&F University, Yangling, China, ${ }^{3}$ Department of Bioengineering, Huanghuai University, Zhumadian, China, ${ }^{4}$ Department of \\ Horticulture, Faculty of Agriculture, Gomal University, Dera Ismail Khan, Pakistan
}

Light is an important environmental factor for fruit development and ripening in pepper plant. Fruit bagging is a significant agrotechnology practiced for the illumination regulation of fruits; some previous researches have shown that fruit bagging could improve the appearance and external quality of fruits and cause them to mature early. However, it would decrease the intrinsic qualities of fruits; especially, fruit bagging could decrease the content of capsanthin in peppers. On the basis of these details, fruit bagging was used as the method of fruit shade stress in this study to explore the characteristics and molecular mechanisms of pepper fruit's color change under shade stress. By using cDNA-AFLP under fruit shading, a fragment related to fruit color was obtained. Next, the full-length coding sequence of the gene was cloned from the pepper fruits. Homologous gene alignment confirmed that the gene has high homology with the rbcL gene, named CarbcL. The function of the CarbcL gene was identified through virus-induced gene silencing (VIGS); it was found that the fruit color changed completely from green to red except for some residue of green fleck when CarbcL gene was silenced, and the green color of fruits had not fully faded in the control group and the empty vector group. The combine determination of chlorophyll content showed that CarbcL was involved in the metabolic control of chlorophyll in pepper fruits; subsequently, HPLC was used to determine the content of capsanthin in pepper fruit which the CarbcL gene was silencing, and it was also found that the content of capsanthin decreased appreciably. These results further confirmed that CarbcL gene was involved in the adjustment of chlorophyll and capsanthin.

Keywords: capsanthin, Capsicum annuum L., fruit chlorophyll breakdown, fruit shading

\section{INTRODUCTION}

In northwestern China, the light intensity is high in summer and the absorption of excess light by plants for photosynthesis may cause photo-oxidative damage. Light intensity can also affect the concentrations of carotenoids and ascorbic acid in fruits and vegetables (Asada, 1994). To overcome the this problem, farmers use shade netting in plastic greenhouses for cultivation, which 
not only decreases the quantity of light but also alters the quality of light to various extents and may affect other environmental factors (Asada, 1994). In recent years, the use of bagging and other methods has greatly improved the appearance and commercial value of fruits and has reduced the amount of pesticide residues on the products (Huang et al., 2009; Yang et al., 2009a). Fruit bagging is currently widely used on fruit trees to produce unblemished, high-quality fruits (Huang et al., 2009; Yang et al., 2009a; Xu et al., 2010). In the past few years, the large-scale use of bagging has become an important process in vegetable production (Seshachala and Tallapragada, 2013) and also has a significant effect on crop yield. For example, bagging in Sorghum was found to increase the carotenoid content by $8-$ $184 \%$ and minimize the exposure of panicles to light (Blessin et al., 1963).

The above-mentioned researches focused only on the general quality and appearance of bagged fruits, but recent studies have shown that bagging also has certain negative effects on fruit development and may affect some qualitative traits (Huang et al., 2009; Xu et al., 2010). Huang et al. (2009) reported that bagging treatments in pear did not affect the total soluble sugar content but did decrease fruit organic acids. Their study further revealed that the levels of chlorophyll, carotenoids, flavonoids, and total phenols did not change much over time after bag removal; however, anthocyanin accumulated quickly (within 10 days) and remained at a constant level (Huang et al., 2009).

In our previous study, it was found that when pepper fruits were bagged at the fruit development stage (green stage), the green color faded earlier (earlier turned red) in bagged fruits than non-bagged fruits. This issue raised questions regarding, regulatory mechanism of fruit color at fruit development stages and genes involvement under shade stress. The Stay Green Rice (SGR) protein is a membrane-bound protein in the chloroplast and was first identified in rice. SGR protein is encoded by $S G R$ gene and it affects chlorophyll degradation during natural and dark-induced leaf senescence in rice (Jiang et al., 2007; Aubry et al., 2008; Barry, 2009). The expression of $S G R$ is closely associated with leaf senescence and fruit ripening (Barry et al., 2008; Yang et al., 2009b). Researches have showed that light affects expression of ribulose-1,5bisphosphate carboxylase/oxygenase $(r b c L)$ gene, light stimulates $r b c L$ transcription, and increases transcription of $r b c L$ (Kim et al., 2002; Sun et al., 2014). RuBisCo content is associated with mRNA level of $r b c L$ (Suzuki et al., 2007). Previous researchers have focused on plant leaves, not fruits for the study of $r b c L$ gene. There is also no report available on the link between chlorophyll and capsanthin. In the present study, we have cleared this phenomenon by using cDNA-AFLP. The pepper fruits were exposed to shade stress at green color stage, and gene expression and its molecular mechanism were studied.

\section{MATERIALS AND METHODS}

\section{Ethics Statement}

This work did not involve endangered or protected species. We abided by the statement of ethical standards for submitted manuscripts, and the manuscript does not describe experiments involving human subjects or animals.

\section{Plant Materials}

Seeds of Capsicum annuum cv.R15 were provided by the Capsicum research group, Department of Horticulture, Northwest A\&F University, P.R. China.

\section{Methods}

\section{Plant Growth Conditions}

To break the dormancy of pepper seeds, pre-sowing treatment of pepper seeds was done as described previously (Tian et al., 2014a). When the seedlings had 8-10 true leaves, they were transplanted into plastic pots under artificial climate chamber; the environmental condition of the artificial climate chamber was day $25^{\circ} \mathrm{C}, 16 \mathrm{~h} /$ night $20^{\circ} \mathrm{C}, 8 \mathrm{~h}$; the relative humidity was $35 \%$, and the light intensity was $370,000 \mu \mathrm{mol} \cdot \mathrm{m}^{-2} \cdot \mathrm{s}^{-1}$. These plastic pots were arranged in a randomized complete block design in the artificial climate chamber. The specifications of plastic pot were $20 \times 14 \mathrm{~cm}$, the soil of pot comprised peat soil, sand, and perlite in the ratio 1:1:1, respectively, and Hoagland nutrient solution was used to provide nutrition for pepper plants.

\section{Fruit Shade Stress}

Pepper fruitlets were marked with labels at anthesis. Fruits of the same size and age were screened and were shaded (bagged) at the mature green stage (25 days after flowering). Specifications of bags: Single story, yellow, paper; length $\times$ width: $75 \mathrm{~mm} \times 150 \mathrm{~mm}$; Transmittance: $8.30 \%$; Air permeability (mL/pa.s): 3.54. Control fruits of the same age and size were not shaded (unbagged) (Tian et al., 2013). After 7 days, fruits from each treatment (shaded or unshaded) were harvested; additional fruits were exposed to light for $4 \mathrm{~h}$ after shade removal and then harvested. The harvested fruits were immediately placed on ice for transport to the laboratory, where the seeds were removed and the peels cut into small pieces and stored at $-80^{\circ} \mathrm{C}$ for further analysis (Tian et al., 2014a).

\section{cDNA-AFLP Analysis of Transcript-derived Fragments (TDFs) Under Fruit Shade Stress}

Total RNA was extracted separately as described previously (Dal Cin et al., 2005) from each sample and used as a template with oligo (dT) 18 as a primer. First-strand cDNAs were synthesized by AMV reverse transcriptase, and the complementary strand was replicated by E. coli DNA polymerase I after the fragments were digested with restriction enzymes (EcoRI and MseI) and ligated. Pre-amplification was performed with the following preamplification primers: EcoRI: 5'-GACTGCGTACCAATTCA-3', MseI: 5'-GATGAGTCCTGAGTAAC-3'. The resulting products were used as templates for selective amplification (Vuylsteke et al., 2007; Yu et al., 2011) with selective primers (Supplementary Table 1). The PCR products were resolved via electrophoresis on a $4 \%$ denaturing polyacrylamide gel, which was then silver-stained and scanned. The fragments of interest were excised from the gel and re-amplified using the same primer combinations and PCR conditions used in the selective amplification (Vuylsteke et al., 2007; Yu et al., 2011). All differentially expressed gene sequences 
were analyzed using the basic local alignment search tool (BLAST) at the National Center for Biotechnology Information (NCBI) website (http://www.ncbi.nlm.nih.gov/blast/) (Vuylsteke et al., 2007; Yu et al., 2011). Among these TDFs, the TDFs related to fruit color were selected for further experiment. The PCR products were subsequently cloned into a pMD19-T vector plasmid (TaKaRa Biotechnology (Dalian) Co., Ltd.) for sequencing.

\section{Virus Vector Construction}

Primers were designed based on the structure of TRV; the upstream primer carried a $K p n I$ site, whereas the downstream primer carried an XhoI site. These primers were used to transfer the target genes into the TRV vector (F: 5'-CGCGGTACC TCGGTCCATACAGTTGTC-3'; R: 5'-GCGCTCGAG GAGT TGTAGGGAGGGATT-3'). Restriction endonucleases (KpnI and XhoI) were used to digest the pTRV2 virus vector and the target gene at $37^{\circ} \mathrm{C}$ overnight (Wang et al., 2013; Tian et al., 2014a), and the digestion products were separated by electrophoresis and ligated to the pTRV2 viral vector using T4 DNA polymerase; the ligation products were transformed into E. coli $\mathrm{DH} 5 \alpha$ cells, and colony PCR was used to detect the target gene fragments. A schematic representation of this vector is shown in Figure 1. The CarbcL gene was cloned into the PTRV2 vector using four fragments from the $3^{\prime}$ end of the open reading frame (Figure 1). The pTRV/00 (empty vector) was used as a negative control.

\section{Cloning of Target Gene Fragments}

Gene fragments used for silencing gene expression must be 150-500 bp in length (Wang et al., 2013). Primers for the PCR amplification of CarbcL were designed according to the sequences of carotenoid-related genes (F: 5'-CGCGGTACC TCGGTCCATACAGTTGTC-3'; R: 5'-GCGCTCGAG GAGTTG TAGGGAGGGATT- $3^{\prime}$ ). Total fruit RNA was purified with Trizol and utilized as a template for cDNA synthesis, which was then used as a template for PCR amplification. The PCR products were separated via agarose gel electrophoresis, and target gene fragments were recovered. The recovered products were then ligated into the cloning vector $\mathrm{pMD} 19$ - $\mathrm{T}$ via overnight incubation with T4 DNA ligase at $16^{\circ} \mathrm{C}$, and the ligation reactions were then transformed into $E$. coli $\mathrm{DH} 5 \alpha$ cells. Plasmids (pTRV2 and PMD19-T) carrying the target genes were digested individually with KpnI and XhoI, and the pTRV2 restriction fragments and target gene fragments were then ligated together (Figure 1).

\section{Genetic Transformation of Agrobacterium}

The pTRV1 and pTRV2 vectors were introduced into Agrobacterium strain GV3101 by freeze-thaw method (Wang et al., 2013). The presence of the vectors in the bacterium was confirmed by PCR, and the bacterial cultures were stored for future use in further experiments.

\section{Virus-induced Gene Silencing (VIGS) and TRV Vector Inoculation into Fruits}

The fruits were washed with distilled water individually, dried at room temperature, and the stalks of the fruits were sealed with melted wax. Then the fruits were sterilized with $75 \%$ alcohol for $30 \mathrm{~s}$ and washed three times with sterilized distilled water in sterilized laminar flow hood. The pTRV1, pTRV2, or pTRV2/CarbcL vector was mixed with Agrobacterium tumefaciens strain GV3101 at a 1:1 ratio. Cultures of Agrobacterium containing pTRV1, pTRV2/00, and pTRV2/CarbcL $\left(\mathrm{OD}_{600}=1.0\right)$ were injected into detached pepper fruits. The TRV vector culture $(0.5 \mathrm{ml})$ was injected at the base of the stalk of each fruit with help of syringe without a needle (Tian et al., 2014a).

The fruits were placed on sterilized filter papers on a stainless steel plate and covered with food-grade cling-film wrap. The plate was placed in a dark chamber $\left(18^{\circ} \mathrm{C}\right.$ with $\left.35 \% \mathrm{RH}\right)$ for 2 days. After 2 days, the treated fruits were transferred to a growth chamber $\left(23^{\circ} \mathrm{C} / 20^{\circ} \mathrm{C}\right.$ under a $16 \mathrm{~h}$ light $/ 8 \mathrm{~h}$ dark cycle with $35 \%$

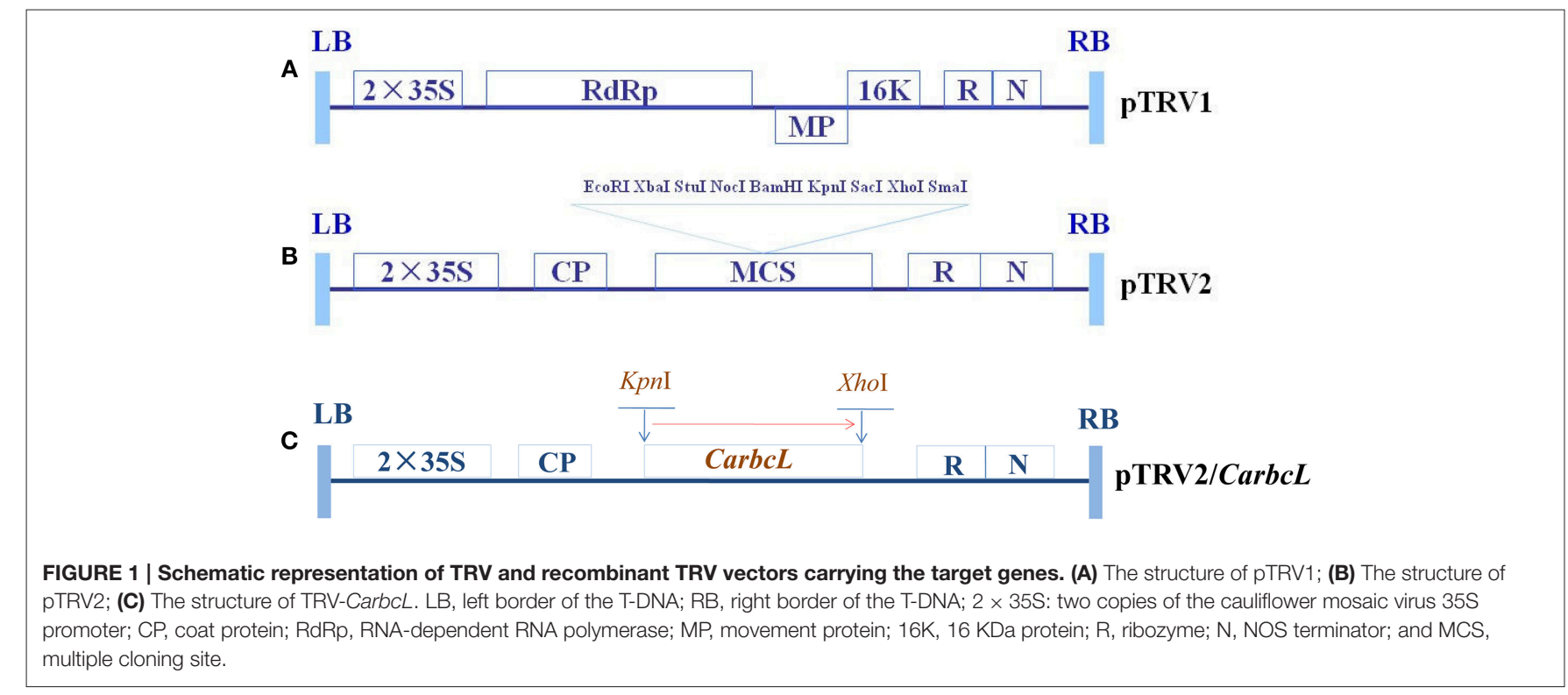


relative humidity). Control (TRV/00) and silenced (TRV/CarbcL) fruits were used for analyses at 15 days after inoculation (Tian et al., 2014a).

\section{Chlorophyll Extraction}

Chlorophyll content was extracted from $10 \mathrm{~g}$ fruit sample in $30 \mathrm{~mL}$ of acetone. The process was repeated till no color left. The extracts were poured into a separating funnel and treated with $100 \mathrm{~mL}$ of diethyl ether. Then, $100 \mathrm{~mL}$ of sodium chloride $(100 \mathrm{~g} / \mathrm{L})$ were added to the mixture. The ethereal layer was separated from the acetone, washed three times with $100 \mathrm{~mL}$ of $50 \mathrm{~g} / \mathrm{L}$ anhydrous $\mathrm{Na}_{2} \mathrm{SO}_{4}$, filtered through a bed of anhydrous $\mathrm{Na}_{2} \mathrm{SO}_{4}$, and left for dryness under vacuum in a rotary evaporator (Switzerland) at $30^{\circ} \mathrm{C}$. The residue was dissolved in $5 \mathrm{~mL}$ of acetone and stored at $-20^{\circ} \mathrm{C}$.

\section{Chlorophylls Analysis for HPLC}

HP1100 Hewlett-Packard liquid chromatograph fitted with an automatic injector and a diode array detector was used for quantification of chlorophylls. A stainless steel column $(25 \times$ $0.46 \mathrm{~cm}$ ), packed with $5 \mu \mathrm{m}$ of C18 HPLC column. The solution of pigments in acetone was centrifuged at 12,000 g (Eppendorf China LTD, Germany) prior to injection into the chromatograph $(20 \mu \mathrm{L})$ (Roca and Miänguez-Mosquera, 2006).

Quantification of the chlorophyll pigments was carried out as described previously (Roca and Miänguez-Mosquera, 2006). Separation was performed using an elution gradient (flow rate) $2 \mathrm{~mL} \mathrm{~min}^{-1}$ with the mobile phases (A) water/ion pair reagent/methanol $(1: 1: 8 \mathrm{v} / \mathrm{v} / \mathrm{v})$ and $(\mathrm{B})$ acetone/methanol (1:1 $\mathrm{v} / \mathrm{v})$. The ion pair reagent was $0.05 \mathrm{~mol} / \mathrm{L}$ tetrabutylammonium acetate and $1 \mathrm{~mol} / \mathrm{L}$ ammonium acetate in water. Detection was performed simultaneously at $666 \mathrm{~nm}$ for series $a$ and $650 \mathrm{~nm}$ for series $b$. Response factors were calculated for each individual pigment by performing calibration plots (peak area ratio vs. concentration ratio) in the presence of a known amount of the pure standard solutions. Chlorophylls (chl) $a$ and $b$ were purchased from Sigma. Chlorophyllide was formed by enzymatic de-esterification of chl. The reaction mixture contained $100 \mathrm{mmol} / \mathrm{L}$ Tris- $\mathrm{HCl}(\mathrm{pH} 8.5)$ containing $0.24 \%$ (w/v) Triton X-100, chl $a$ dissolved in acetone, and crude enzymatic extract from fruits in a 5:1:5 (v/v/v) ratio. The C-13 epimer of Chl $(a$ or $b)$ was prepared by treatment with chloroform. $13^{2}$ $\mathrm{OH}-\mathrm{Chl}(a$ or $b$ ) was obtained by selenium dioxide oxidation of $\mathrm{Chl}$ at reflux heating for $4 \mathrm{~h}$ in pyridine solution under argon. All $\mathrm{Mg}$-free derivatives were obtained from the corresponding $\mathrm{Chl}$ parent dissolved in diethyl ether by acidification with 2-3 drops of $5 \mathrm{~mol} / \mathrm{L} \mathrm{HCl}$. All standards were purified by normal phase (NP) and reversed phase (RP) thin-layer chromatography (TLC) (Roca and Miänguez-Mosquera, 2006).

\section{Capsanthin Extraction and Analysis}

Capsanthin was extracted as described previously (Tian et al., 2014a). A $5.0 \mathrm{~g}$ sample of pericarp tissue was extracted with $5 \mathrm{ml}$ of acetone containing $0.1 \%$ butylated hydroxytoluene (BHT). After shaking and incubation on ice in the dark for $10 \mathrm{~min}$, the mixture was centrifuged at $3500 \mathrm{rpm}$ for $10 \mathrm{~min}$ at room temperature and the extract was transferred to a clean tube. Samples were re-extracted twice with $5.0 \mathrm{ml}$ of acetone containing $0.1 \%$ BHT. Pooled extracts were dried under a nitrogen flow, and the tubes were sealed and stored at $-20^{\circ} \mathrm{C}$ until high pressure liquid chromatography (HPLC) analysis. HPLC was performed as described previously (Tian et al., 2014a). For HPLC, samples $(20 \mu \mathrm{L})$ were analyzed on a shimpack VP-ODS C-18 HPLC column $(5 \mu \mathrm{m}, 150 \times 4.6 \mathrm{~mm})$. The eluent consisted of acetonitrile: 2-propanol: water in the ratio of 39:53:8 (A), respectively, and acetonitrile: 2-propanol in the ratio of $60: 40$ (B), respectively. The gradient profile was set $0-30 \mathrm{~min}$ from 0 to $100 \% \mathrm{~B}$. The flow rate was set at $0.3 \mathrm{~mL} / \mathrm{min}$ and the column temperature at $40^{\circ} \mathrm{C}$. Standard solution of capsanthin $(0.001-0.1 \mathrm{mg} / \mathrm{mL})$ was used to make calibration curve at $454 \mathrm{~nm}$. The capsanthin was identified by their absorption spectra as captured by the photodiode array detector and HPLC retention times in comparison with authentic standards. In addition, samples were spiked with standards to verify the identity of sample peaks with similar retention times. Capsanthin was purchased from Extrasynthèse (Genay, France), and it was used as authentic standards. The standard was handled under low light conditions on ice. Standard solution of capsanthin standard consisted methanol and acetonitrile in the ratio 1:1 (V/V). Aliquots were diluted in methanol:acetonitrile (1:1) solution to provide standard concentrations (Tian et al., 2014a). Each value was the mean of three biological replicates.

\section{RNA Isolation and qRT-PCR Analysis}

The fruits (treated and non-treated) were used for total RNA extraction. RNA was extracted through Trizol (Invitrogen) and quantified through NanoDrop spectrophotometer (Nano Drop 2000c, Thermo Scientific, Wilmington, USA) (Wang et al., 2009, 2013; Tian et al., 2014b). First-strand cDNA was synthesized from $500 \mathrm{ng}$ of total RNA using a PrimeScript ${ }^{\mathrm{TM}}$ Kit (TaKaRa, Bio Inc., China) following the manufacturer's protocols. qRTPCR was performed using SYBR ${ }^{\circledR}$ Premix Ex Taq ${ }^{\text {TM }}$ II (TaKaRa, Bio Inc., China) with $10.0 \mu \mathrm{l} \mathrm{SYBR}^{\circledR}$ Premix Ex Taq ${ }^{\mathrm{TM}}$ II, $2.0 \mu \mathrm{l}$ diluted cDNA, and $0.8 \mu 1$ forward and reverse primers with total volume of $20 \mu \mathrm{l}$ (Wang et al., 2013; Tian et al., 2014a,b). The qRT-PCR condition was maintained at $95^{\circ} \mathrm{C}$ for $1 \mathrm{~min}$, followed by 45 cycles at $95^{\circ} \mathrm{C}$ for $10 \mathrm{~s}, 50^{\circ} \mathrm{C}$ for $30 \mathrm{~s}$, and $72^{\circ} \mathrm{C}$ for $20 \mathrm{~s}$, and primers F:5'-GAGTTGTAGGGAGGGATT-3'; R:5' TCGGTCCATACAGTTGTC-3', while Ubi3 (AY486137.1) was used as an internal control (Wan et al., 2011). The $\Delta \Delta \mathrm{Ct}$ method was used for relative expression levels of each gene (Livak and Schmittgen, 2001). The treatments were replicated thrice as well as experiment to minimize the error.

\section{Statistical Analysis}

SAS 6.12 software (SAS Institute, Gary, North Carolina) was used for data analysis. All measured values were presented as mean \pm standard error of the means. Duncan's multiple-range test was chosen, and LSR (Least significant ranges) analysis at $5 \%$ significantly different is shown in lowercase letters ( $a$ and b) (Duncan, 1995). Means with the same letter are not significantly different. Figures were drawn using Sigma Plot 10.0 software; all experiments were carried out in triplicate. 


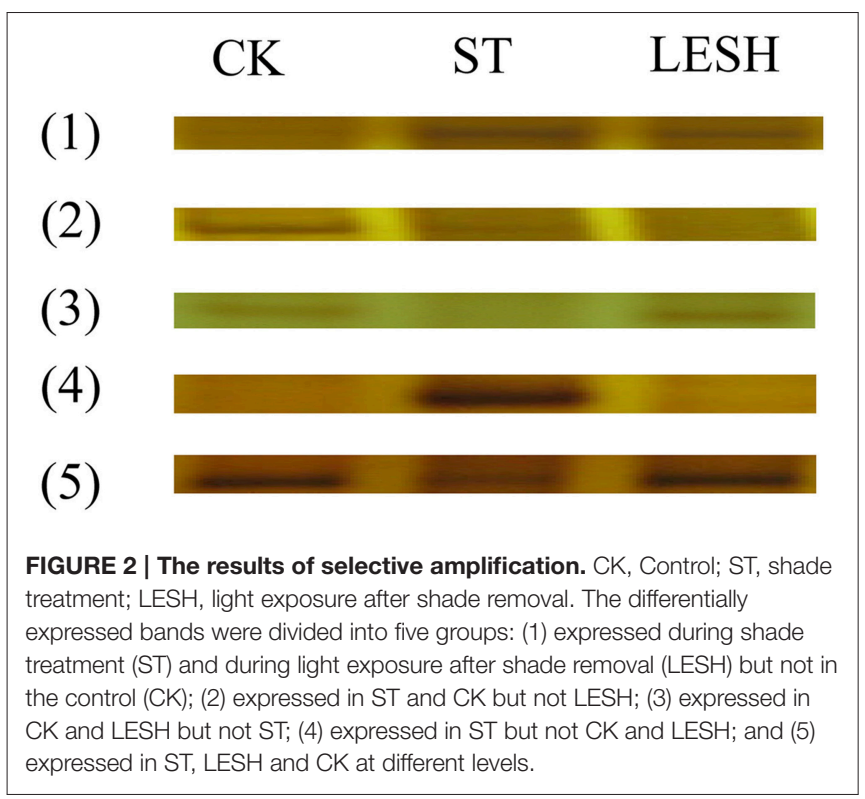

\section{RESULTS}

\section{Identification of Differentially Expressed TDFs}

Primers (64 pairs) were randomly applied for selective cDNAAFLP amplification (Supplementary Table 1). The 80 clear bands with differential expression were revealed by analyzing the shaded fruits, the fruits that were exposed to light for $4 \mathrm{~h}$ after shade removal, and the control fruits (unbagged). These bands were divided into five groups: (1) expressed during shade treatment (ST) and during light exposure after shade removal (LESH) but not in the control (CK); (2) expressed in ST and CK but not LESH; (3) expressed in CK and LESH but not ST; (4) expressed in ST but not CK and LESH; and (5) expressed in ST, LESH, and CK at different levels. All of differential expression bands were excised from SDS-polyacrylamide gel and to renew amplifies by PCR using these differential bands as templates; finally, these differential bands were separated by agarose gel electrophoresis, and the new bands were excised from agarose gel and transformed into Escherichia coli for DNA sequencing. Figure 2 shows the differentially expressed bands.

\section{Sequence Analysis of TDFs}

A total of 80 reproducible TDFs were identified with 64 primer combinations tested. All of these TDFs were cloned and sequenced as described previously (Vuylsteke et al., 2007; Yu et al., 2011; Lin et al., 2014). All differentially expressed gene sequences were analyzed using the basic local alignment search tool (BLAST) at the National Center for Biotechnology Information (NCBI) website (http://www. ncbi.nlm.nih.gov/blast/). Among these TDFs, 27 bands were differently expressed, and the homology results were obtained with BLAST analysis (Supplementary Table 2). They were DNA-binding protein, ubiquitin-proteasome, HTC in leaf,
$26 \mathrm{~s}$ ribosomal RNA and transcription elongation factor, etc. (Supplementary Table 2), but only one TDF (GenBank: KT779503) was related to chlorophyll metabolism in fruit; the TDF is, perhaps, involved in the regulation and control of chlorophyll under fruit shade stress during pepper fruit development and ripening.

\section{Cloning and Sequencing of the Full-length Gene}

Based on BLAST analysis, the TDF (namely, subsequent CarbcL gene) related to chlorophyll metabolism in fruit was cloned. BLAST was used to identify a particular TDF relevant to chlorophyll synthesis. Based on the data obtained from GenBank and the pepper genome database (http://peppersequence. genomics.cn/page/species/blast) and RACE methods, we obtained a fragment of approximately $1364 \mathrm{bp}$. Sequencing and homology analyses showed that the full-length sequence is 1364 bp (GenBank: KT779528).

\section{Alignment of Homologous Genes}

The base sequence (GenBank: KT779528) was put into NCBI/BLAST/blastn suite; it was found that the sequence of the cloned Capsicum gene is highly homologous to the ribulose-1,5bisphosphate carboxylase/oxygenase gene (GenBank: KT779528) (Figure 3), with a similarity of $99 \%$, so it was named CarbcL. Then, the gene sequence was evaluated using the pepper genome database (http://peppersequence.genomics.cn/ page/species/blast). The sequence of CarbcL gene showed a 98\% homology with the Capana12g001789 (http://peppersequence. genomics.cn).

\section{Functional Analysis of CarbcL by VIGS}

VIGS technology was used to further verify whether the gene is involved in the metabolic control of chlorophyll. TRV viral vectors, pTRV1 and pTRV2, were constructed as gene-silencing vectors for a preliminary determination of gene function in detached pepper fruits (Tian et al., 2014a). The detached pepper fruits in which the target gene was silenced showed symptoms of chlorosis on day 7 of treatment, and the symptoms were obvious on day 10. The fruit color was dark green before injection but changed after 10 days of treatment (Figure 4). The fruits in the control (WT fruits) and empty vector (TRV/00) groups were eventually turned brown, whereas the fruits in the silenced (TRV/CarbcL) group had turned red after 10 days of treatment, with only some green spots remaining. This result shows that the CarbcL gene was involved in the color control of fruit in pepper. RNA was extracted from the WT (control), TRV/00 (empty vector), and TRV/CarbcL (genesilenced) fruits and reverse transcribed into cDNA using qRTPCR to analyze the mRNA expression levels of CarbcL. As there were no differences in the levels of $C a r b c L$ mRNA between the WT fruits (control group) and TRV/00 (empty vector) fruits, the impact of the TRV virus vector was negligible. However, the expression level of CarbcL significantly decreased in the CarbcL-silenced fruits (Figure 5A), with a silencing efficiency of $81 \%$. These results demonstrate that the green color of pepper 


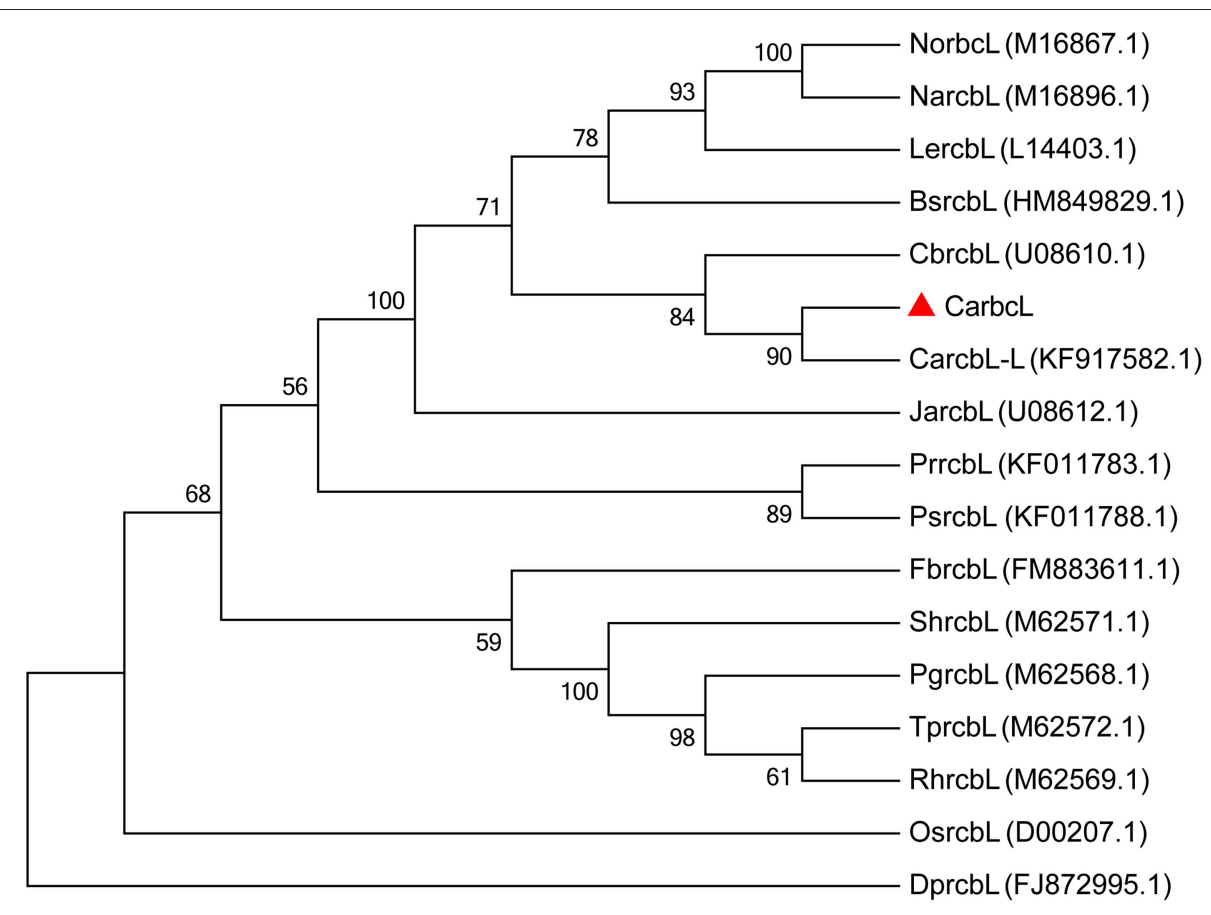

FIGURE 3 | The phylogenetic tree of CarbcL and other related sequences. Numbers below the branches are the neighbor-joining bootstrap values; CarbcL gene was marked with "^" symbol; GenBank accession numbers: (Tobacco) NorbcL, M16867.1; (Lycopersicon esculentum) LercbL, L14403.1; (Brugmansia suaveolens) BsrcbL, HM849829.1; (Juanulloa aurantiaca) JarcbL, U08612.1; (Capsicum baccatum) CbrcbL, U08610.1; (Capsicum annuum) CarcbL-L, KF917582.1; (N. acuminata) NarcbL, M16896.1; (T. portulacastrum) TprcbL, M62572.1; (Durvillaea potatorum) DprcbL, FJ872995.1; (Pedicularis rex) PrrcbL, KF011783.1;

(Pedicularis superba) PsrcbL, KF011788.1; (Fallopiax bohemica) FbrcbL, FM883611.1; (Portulaca grandiflora) PgrcbL, M62568.1; (S. halimifolium) ShrcbL, M62571.1; (R. humilis) RhrcbL, M62569.1; (Oryza sativa) OsrcbL, D00207.1.

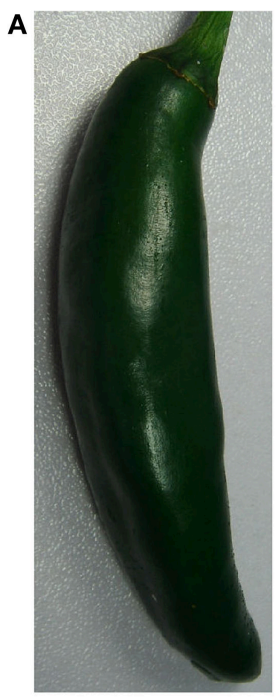

Before Injection
B

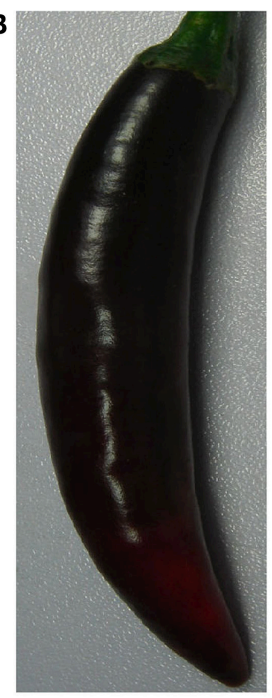

WT-Fruits

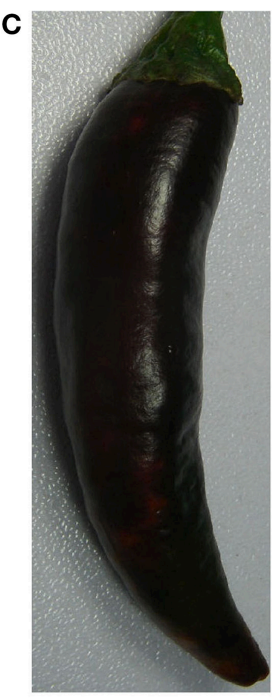

TRV/00

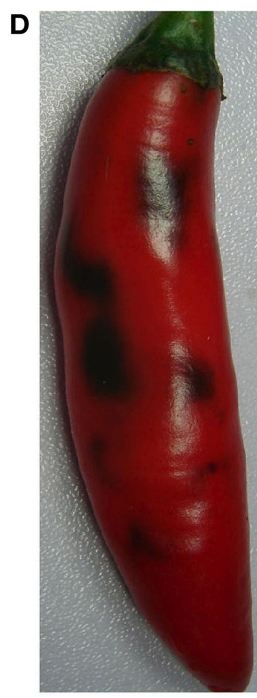

TRV/CarbcL

FIGURE 4 | Phenotypes of plants after CarbcL gene silencing. (A) Before injection, the color of fruits before the sample was treated; (B) WT-Fruits, the color of fruits in the control group after 10 days; (C) TRV/00, the color of fruits in the empty vector group after 10 days; (D) TRV/CarbcL, the color of fruits in the treatment group (fruits were injected TRV/CarbcL) after 10 days of treatment. 

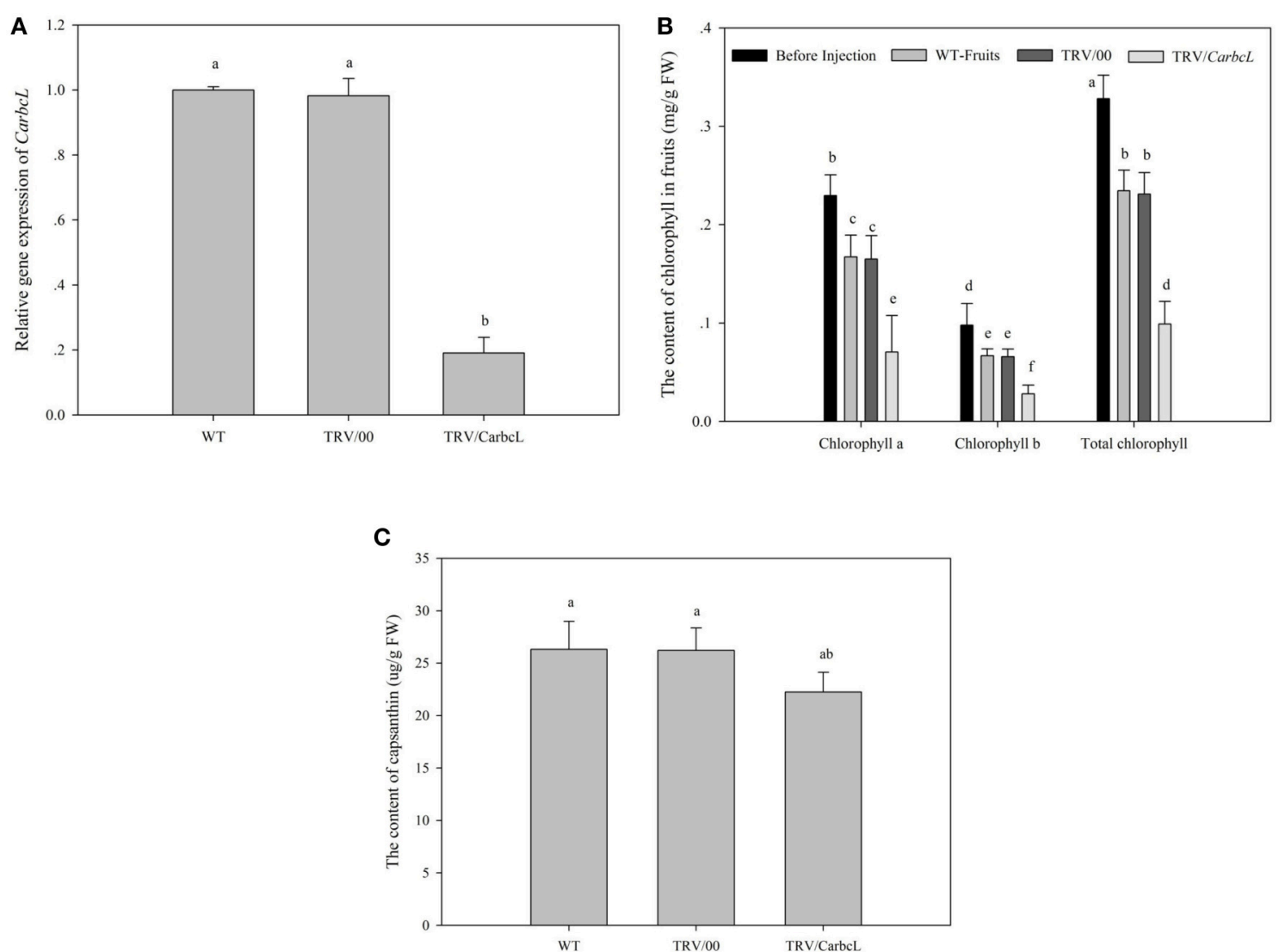

FIGURE 5 | Changes in gene expression level, chlorophyll content and fruit capsanthin content after gene silencing. WT, the control group; TRV/00, the empty vector group; TRV/CarbcL, the treatment group. (A) The changes in gene expression level after silencing; Ubi3 (AY486137.1) was used as an internal control by using qRT-PCR; (B) the changes in fruit chlorophyll content after gene silencing; Before injection, the content of chlorophyll before the sample was treated; WT-Fruits, the content of chlorophyll in the control group; TRV/O0, the content of chlorophyll in the empty vector group after 10 days of treatment; TRV/CarbcL, the content of chlorophyll in the treatment group (fruits were injected TRV/CarbcL) after 10 days of treatment; (C) the changes in fruit capsanthin content after gene silencing; the content of capsanthin in the control group; TRV/O0, the content of capsanthin in the empty vector group; TRV/CarbcL, the content of capsanthin in the treatment group; LSR analysis at $5 \%$ is shown in lowercase letters ( $a$ and $b)$. Means with the same letter are not significantly different. All experiments were carried out in triplicate.

fruits from the TRV/CarbcL plants faded due to silencing of the CarbcL gene.

\section{Expression Analysis of CarbcL Gene after VIGS}

As everybody knows, the effect of gene silencing by VIGS was measured by the expression level of gene. After CarbcL gene was silenced, the expression level of CarbcL gene was analyzed in the WT fruits (control group) and the silenced (TRV/CarbcL) group. The result showed that the expression level of CarbcL gene significantly decreased after CarbcL gene was silenced; the expression level (TRV/CarbcL) was about 19\% of the control group (WT) (Figure 5A). There were indications that the silencing effects of gene were ideal; it could be used as the basis of the gene function confirmation. From Figure 5A, it could reveal that there were no differences in the expression levels of CarbcL between the control group (WT) and the empty vector (TRV/00); the impact of the TRV virus vector was negligible. However, the expression level of CarbcL was very lower in the silenced (TRV/CarbcL) group than that of the control group
(WT) (Figure 5A). This demonstrated that the fading of green color in pepper fruits was caused by CarbcL gene silencing (Figures 4D, 5A). This further proved that the green color of pepper fruit was closely related to $\operatorname{CarbcL}$ gene.

\section{Changes in the Chlorophyll Content of TRV/CarbcL Pepper Fruits}

By comparing the chlorophyll content of the control fruit (WTFruits), the empty vector fruit (TRV/00), and fruit of gene silencing (TRV/CarbcL), it was found that the green color of fruit disappeared after 10 days except for some residue of green fleck when CarbcL gene was silenced; the color of fruit changed completely from green to red (Figures 4A,D); but the surface of the control group (WT-Fruits) kept a lot of green color, and the fruits presented a brownish red color (Figure 4B). To check again for the empty vector fruit (TRV/00), it was found that the color of the fruit was brownish red also (Figure 4C); There was no obvious difference in the color of fruits between the control fruit (WT-Fruits) and the empty vector fruit (TRV/00) (Figures 4B,C). This demonstrated that TRV vector had no 
impact on the color of fruit; the fading of green color of fruit (TRV/CarbcL) was due to CarbcL gene silencing (Figure 4D). For further study about the relationship between CarbcL and chlorophyll, the chlorophyll content was determined in the control (WT-Fruits) and the treatment (TRV/CarbcL). The result showed that the chlorophyll content was much lower in the CarbcL-silenced pepper fruits (TRV/CarbcL) than in the control fruits (WT-Fruits) (Figure 5B). These results showed that the CarbcL gene is involved in the metabolic control of chlorophyll in pepper fruits.

\section{Changes in the Capsanthin Content of Pepper Fruits When Silencing CarbcL}

After CarbcL gene silencing, the content of capsanthin was determined in the treatment group (TRV/CarbcL), the control group (WT), and the empty vector group (TRV/00). The result showed that the content of capsanthin was same basically in the control group (WT) and the empty vector group (TRV/00). A statistical analysis was made on capsanthin content among the three groups (WT, TRV/00, and TRV/CarbcL); it was found that the difference between the control group (WT) and the empty vector group (TRV/00) was not significant. However, when the content of capsanthin was determined in the treatment group (TRV/CarbcL), it was found that the content of capsanthin was lower than the control (WT) and the empty vector group (TRV/00). There were some differences in the content of capsanthin between the control group (WT) and treatment group (TRV/CarbcL) through statistical analysis. These results indicated that not only the normal metabolism of chlorophyll was affected but also the synthesis of capsanthin was also affected when $C a r b c L$ was silenced. The measuring result showed that the capsanthin content was reduced by $15.4 \%$ in the CarbcL-silenced pepper fruits than that in the control fruits (Figure 5C). This result also confirms that the CarbcL gene is also associated with synthesis of capsanthin in pepper fruits.

\section{Further Confirmation of CarbcL Gene Expression Under Shade Stress}

To further confirm the relationship of CarbcL gene and metabolic control of chlorophyll in pepper fruits, the initial experiment was repeated (a phenomenon of the green color of fruit fading under fruit shade stress). Specifically, pepper fruits were shaded by bagging for 7 days to renew shade stress for pepper fruits and to observe the change of pepper fruit color, the content of chlorophyll, and CarbcL mRNA expression level. As shown by the experimental results, after pepper fruits were shaded by bagging for 7 days, a greater and an obvious change had taken place in fruit color (Figure 6A). Comparing with the control, the color of fruit changed from dark green to a pale green (Figure 6A). Meanwhile, by determining the content of chlorophyll, it was found the content of chlorophyll decreased a lot (Figure 6B). Additionally, CarbcL gene expression level was significantly reduced in the treatment fruits (Figure 6C). Therefore, it was shade stress that the expression of CarbcL gene was repressed, thereby resulting in the degradation of chlorophyll to cause a phenomenon of fruit fading. This provides further evidence that CarbcL is involved in the metabolic control of chlorophyll and that $C a r b c L$ is a light-sensitive gene.

\section{DISCUSSION}

In our experiment, the CarbcL gene was cloned and characterized. Experimental results showed that the gene was related to chlorophyll in pepper fruits, and it is a RuBisCo largesubunit gene $(r b c L)$. We know that RuBisCo is a plant metabolic enzyme that converts carbon dioxide from the atmosphere into organic carbon in the rate-limiting step of the Calvin cycle. It specifically catalyzes the carboxylation of d-ribulose1,5-bisphosphate to form an unstable 6-carbon intermediate (Raven, 2013). In higher plants, RuBisCo is composed of eight small subunits encoded by a nuclear multigene family $(r b c S)$ (Dean et al., 1989) and eight large subunits encoded by a single gene $(r b c L)$ in the chloroplast genome (Rodermel et al., 1996). $\mathrm{RuBisCo}$ content increases rapidly during leaf expansion, reaches to maximum level at maturation, and then declines gradually during senescence stage (Imai et al., 2005; Suzuki et al., 2009b). A decrease in RuBisCo activity is a hallmark of senescence (Secor et al., 1984; Ford and Shibles, 1988; Crafts-Brandner, 1992). Light affect expression of $r b c L$ gene stimulates $r b c L$ transcription and increases the transcription of $r b c L$ (Kim et al., 2002; Sun et al., 2014). Low light had significant effect on RuBisCo; it down-regulated the gene expression of RuBisCo at transcript levels and resulted in the loss and inactivation of RuBisCo large subunit (Sui et al., 2011; Sun et al., 2014).

By a series of experiments, the CarbcL gene was screened and cloned in pepper fruits by cDNA-AFLP under shade stress. Bioinformatics analysis indicated that CarbcL gene is associated with the metabolic control of chlorophyll. Silencing of CarbcL through VIGS technology in pepper fruits caused green fruits to fade early and turn red (Figure 4), and the expression level of CarbcL was strikingly reduced in the silenced lines (Figure 5A). Furthermore, the expression of CarbcL in shade-stressed fruits was very low (Figure 6C) during color changing from dark green to light green (Figure 6A) and the chlorophyll content considerably reduced (Figure 6B). The above experiment proved that $C a r b c L$ played an important role in the metabolic control of chlorophyll in pepper fruits. It was also found that capsanthin content was slightly reduced when $C a r b c L$ was silenced in pepper fruits (Figure 5C). This confirmed that inhibition of CarbcL gene caused not only chlorophyll degradation (Figure 5B) but also capsanthin content reduction (Figure 5C). Furthermore, CarbcL could not express normally under shade stress and shade stress caused chlorophyll degradation of fruits (Figure 6). These results further confirmed that CarbcL controlled chlorophyll metabolism in pepper fruits and is a light-sensitive gene. It was also noteworthy that $S G R$ gene was not screened from all the differentially expressed fragments in our experiments. This showed that $S G R$ gene did not play an important role in the metabolic control of chlorophyll under shade stress in pepper, although the $S G R$ protein affects chlorophyll degradation during natural and dark-induced leaf senescence in rice (Jiang et al., 2007; Aubry et al., 2008; Barry, 2009). The results of current study 

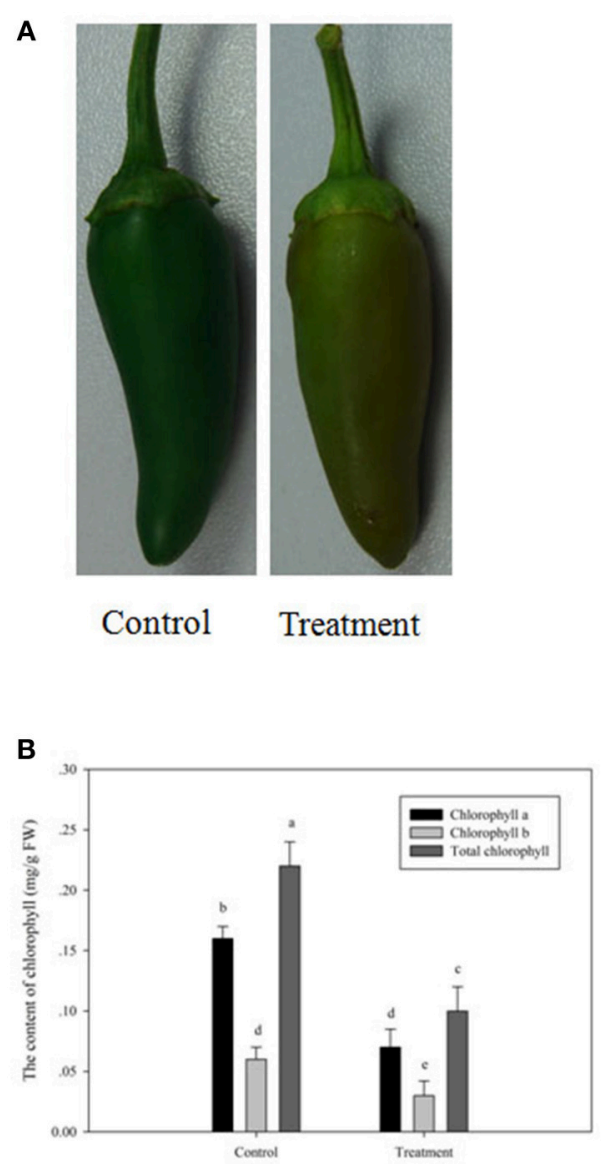

C

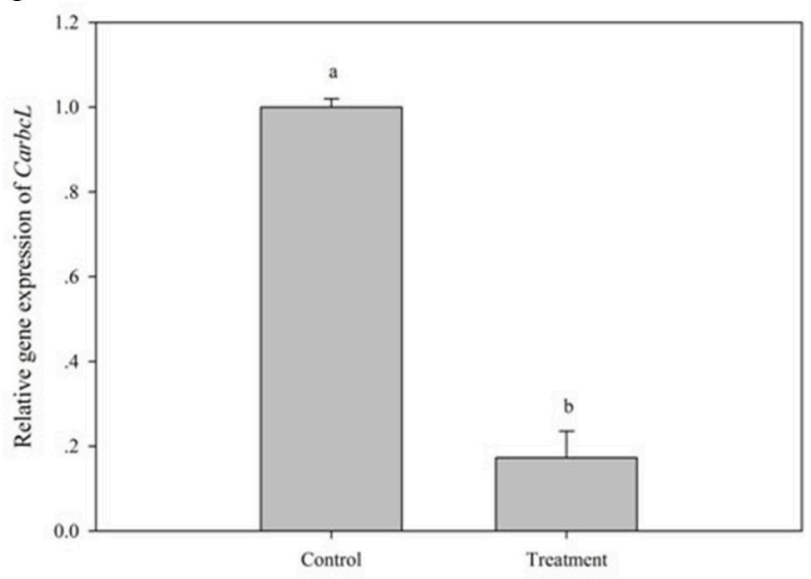

CarbcL

Ubi3

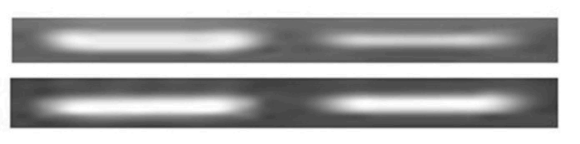

Control

Treatment

FIGURE 6 | Changes in fruit phenotype, chlorophyll content and CarbcL gene expression under low light. (A) Phenotypic differences in fruits of the control and treatment groups. (B) Differences in the chlorophyll content of fruits in the control and treatment groups. (C) Gene expression differences in fruits of the control and treatment groups; Control: the control group (Fruits with no shade stress), Treatment: the treatment group (Fruits with shade stress). LSR analysis at $5 \%$ is shown in lowercase letters ( $\mathrm{a}$ and $\mathrm{b})$. Means with the same letter are not significantly different. All experiments were carried out in triplicate.

will provide platform for future studies and have elucidated the regulatory mechanism that how low light (shade) influences fruit color during pepper fruit development.

\section{CONCLUSIONS}

By cloning and characterization of the CarbcL gene, it was found that $C a r b c L$ participated in the metabolic control of chlorophyll. The gene $(\mathrm{CarbcL})$ is very similar to Ribulose-1,5-bisphosphate carboxylase/oxygenase (RuBisCo large subunit). The function of the CarbcL gene was identified through virus-induced gene silencing (VIGS). The fruit color was changed completely from green to red except for some residue of green fleck when CarbcL gene was silenced, whereas the green color of fruits had not fully faded in the control group and the empty vector group. In the combine determination of chlorophyll content, CarbcL was found to be involved in the metabolic control of chlorophyll in pepper fruits. It was also found that the capsanthin content decreased appreciably after $C a r b c L$ gene silencing. It was further confirmed that CarbcL involved in the synthesis of chlorophyll and capsanthin. Under the shade stress, it was also found that CarbcL gene was repressed and caused chlorophyll degradation. This provides further evidence that CarbcL is involved in the metabolic control of chlorophyll and that CarbcL is a lightsensitive gene.

\section{ACKNOWLEDGMENTS}

The following organizations are acknowledged for their financial support: the National Natural Science Foundation of China (No. 31272163), the Jiangsu Agricultural Science and Technology Innovation Fund [CX (12)1004] and the Shaanxi Provincial Science and Technology Coordinating Innovative Engineering Project (2012KTCL02-09).

\section{SUPPLEMENTARY MATERIAL}

The Supplementary Material for this article can be found online at: http://journal.frontiersin.org/article/10.3389/fpls.2015. 00850 


\section{REFERENCES}

Asada, K. (1994). "Production and active oxygen specics in photosynthetic tissues," in Causes of Photoxidative Stress and Amelioration of Defence Systems in Plants, eds C. H. Foyer and P. M. Mullincaux (Boca Raton, FL: CRC Press), 11-104.

Aubry, S., Mani, J., and Hörtensteiner, S. (2008). Stay-green protein, defective in Mendel's green cotyledon mutant, acts independent and upstream of pheophorbide a oxygenase in the chlorophyll catabolic pathway. Plant Mol. Biol. 67, 243-256. doi: 10.1007/s11103-008-9314-8

Barry, C. S. (2009). The stay-green revolution: recent progress in deciphering the mechanisms of chlorophyll degradation in higher plants. Plant Sci. 176, 325-333. doi: 10.1016/j.plantsci.2008.12.013

Barry, C. S., McQuinn, R. P., Chung, M. Y., Besuden, A., and Giovannoni, J. J. (2008). Amino acid substitutions in homologs of the stay-green protein are responsible for the green-flesh and chlorophyll retainer mutations of tomato and pepper. Plant Physiol. 147, 179-187. doi: 10.1104/pp.108.118430

Blessin, C. W., Brecher, J. D., and Dimler, R. J. (1963). Carotenoids of corn and sorghum: distribution of xanthophylls and carotenes in hand-dissected and dry-milled fractions of yellow dent corn. Cereal Chem. 40, 582-590.

Crafts-Brandner, S. J. (1992). Phosphorus-nutrition influence on leaf senescence in soybean. Plant Physiol. 98, 1128-1132. doi: 10.1104/pp.98.3.1128

Dal Cin, V., Danesin, M., Rizzini, F. M., and Ramina, A. (2005). RNA extraction from plant tissues. Mol. Biotechnol. 31, 113-119. doi: 10.1385/MB:31:2:113

Dean, C., Pichersky, E., and Dunsmuir, P. (1989). Structure, evolution, and regulation of Rbcs genes in higher-plants. Annu. Rev. Plant Physiol. Mol. Biol. 40, 415-439. doi: 10.1146/annurev.pp.40.060189.002215

Duncan, D. B. (1995). Multiple range and multiple F tests. Biometrics 1, 1-42.

Ford, D. M., and Shibles, R. (1988). Photosynthesis and other traits in relation to chloroplast number during soybean leaf senescence. Plant Physiol. 86, 108-111. doi: $10.1104 /$ pp.86.1.108

Huang, C. H., Yu, B., Teng, Y. W., Su, J., Shu, Q., Cheng, Z. Q., et al. (2009). Effects of fruit bagging on coloring and related physiology, and qualities of red Chinese sand pears during fruit maturation. Sci. Hortic. 121, 149-158. doi: 10.1016/j.scienta.2009.01.031

Imai, K., Suzuki, Y., Makino, A., and Mae, T. (2005). Effects of nitrogen nutrition on the relationships between the levels of rbcS and $\mathrm{rbcL}$ mRNAs and the amount of ribulose 1,5-bisphosphate carboxylase/oxygenase synthesized in the eighth leaves of rice from emergence through senescence. Plant Cell Environ. 28, 1589-1600. doi: 10.1111/j.1365-3040.2005.01438.x

Jiang, H., Li, M., Liang, N., Yan, H., Wei, Y., Xu, X., et al. (2007). Molecular cloning and function analysis of the stay green gene in rice. Plant J. 52, 197-209. doi: 10.1111/j.1365-313X.2007.03221.x

Kim, J. W., Park, J. K., Kim, B. H., Lee, J. S., and Sim, W. S. (2002). Molecular analysis of the accumulation of the transcripts of the large subunit gene of Ribulose-1,5-bisphosphate carboxylase/oxygenase by light. Mol. Cells 14, 281-287.

Lin, H. Z., Lin, W. D., Lin, C. Y., Peng, S. F., and Cheng, Y. M. (2014). Characterization of maize B-chromosome-related transcripts isolated via cDNA-AFLP. Chromosoma 123, 597-607. doi: 10.1007/s00412-014-0476-7

Livak, K. J., and Schmittgen, T. D. (2001). Analysis of relative gene expression data using real-time quantitative PCR and the $2(\mathrm{~T})(-$ Delta Delta C) method. Methods 25, 402-408. doi: 10.1006/meth.2001.1262

Raven, J. A. (2013). Rubisco: still the most abundant protein of Earth. New Phytol. 198, 1-3. doi: 10.1111/nph.12197

Roca, M., and Miänguez-Mosquera, M. I. (2006). Chlorophyll catabolism pathway in fruits of Capsicum annuum L.: stay-green versus red fruits. J. Agric. Food Chem. 54, 4035-4040. doi: 10.1021/jf060213t

Rodermel, S., Haley, J., Jiang, C. Z., Tsai, C. H., and Bogorad, L. (1996). A mechanism for intergenomic integration: abundance of ribulose bisphosphate carboxylase smallsubunit protein influences the translation of the largesubunit mRNA. Proc. Natl. Acad. Sci. U.S.A. 93, 3881-3885. doi: 10.1073/pnas.93.9.3881

Secor, J., Shibles, R., and Stewart, C. R. (1984). A metabolic comparison between progressive and monocarpic senescence of soybean. Can. J. Bot. 62, 806-811. doi: 10.1139/b84-117

Seshachala, U., and Tallapragada, P. (2013). Anti microbial and antioxidant activity of pepper extracts. Res. J. Biotechnol. 8, 65-71.
Sui, X. L., Sun, J. L., Wang, S. H., Li, W., Hu, L. P., Meng, F. Z., et al. (2011). Photosynthetic induction in leaves of two cucumber genotypes differing in sensitivity to low-light stress. Afr. J. Biotech. 10, 2238-2247.

Sun, J. L., Sui, X. L., Huang, H. Y., Wang, S. L., Wei, Y. X., and Zhang, Z. X. (2014). Low light stress down-regulated Rubisco gene expression and photosynthetic capacity during Cucumber (Cucumis sativus L.) leaf development. J. Integr. Agric. 13, 997-1007. doi: 10.1016/S2095-3119(13)60670-X

Suzuki, Y., Nakabayashi, K., Yoshizawa, R., Mae, T., and Makino, A. (2009b). Differences in expression of the RBCS multigene family and Rubisco protein content in various rice plant tissues at different growth stages. Plant Cell Physiol. 50, 1851-1855. doi: 10.1093/pcp/pcp120

Suzuki, Y., Ohkubo, M., Hatakeyama, H., Ohashi, K., Yoshizawa, R., Kojima, S., et al. (2007). Increased Rubisco content in transgenic rice transformed with the "sense" rbcS gene. Plant Cell Physiol. 48, 626-637. doi: 10.1093/pcp/ pcm035

Tian, S. L., Gong, Z. H., Du, X. H., and Shah, S. N. M. (2013). Effects of fruit bagging on capsanthin and expression of key genes in the capsanthin biosynthetic pathway during fruit development and ripening of the pepper. Res. J. Biotechnol. 8, 118-123.

Tian, S. L., Li, L., Chai, W. G., Shah, S. N., and Gong, Z. H. (2014a). Effects of silencing key genes in the capsanthin biosynthetic pathway on fruit color of detached pepper fruits. BMC Plant Biol. 14:314. doi: 10.1186/s12870-0140314-3

Tian, S. L., Lu, B. Y., Gong, Z. H., and Shah, S. N. M. (2014b). Effects of drought stress on capsanthin during fruit development and ripening in pepper (Capsicum annuumL.). Agric. Water Manage. 137, 46-51. doi: 10.1016/j.agwat.2014.02.007

Vuylsteke, M., Peleman, J. D., and van Eijk, M. J. (2007). AFLP-based transcript profiling (cDNA-AFLP) for genome-wide expression analysis. Nat. Protoc. 2, 1399-1413. doi: 10.1038/nprot.2007.174

Wan, H., Yuan, W., Ruan, M., Ye, Q, Wang, R., Li, Z. M., et al. (2011). Identification of reference genes for reverse transcription quantitative real-time PCR normalization in pepper (Capsicum annuum L.). Biochem. Biophys. Res. Comnun. 416, 24-30. doi: 10.1016/j.bbrc.2011.10.105

Wang, H. M., Yin, W. C., Wang, C. K., and To, K. Y. (2009). Isolation of functional RNA from different tissues of tomato suitable for developmental profiling by microarray analysis. Bot. Stud. 50, 115-125.

Wang, J. E., Liu, K. K., Li, D. W., Zhang, Y. L., Zhao, Q., He, Y. M., et al. (2013). A novel peroxidase $C a P O D$ gene of pepper is involved in defense responses to phytophtora capsici Infection as well as abiotic stress tolerance. Int. J. Mol. Sci. 14, 3158-3177. doi: 10.3390/ijms14023158

Xu, H. X., Chen, J. W., and Xie, M. (2010). Effect of different light transmittance paper bags on fruit quality and antioxidant capacity in loquat. J. Sci. Food Agric. 90, 1783-1788. doi: 10.1002/jsfa.4012

Yang, W. H., Zhu, X. C., Bu, J. H., Hu, G. B., Wang, H. C., and Huang, X. M. (2009a). Effects of bagging on fruit development and quality in crosswinter off-season longan. Sci. Hortic. 120, 194-200. doi: 10.1016/j.scienta.2008. 10.009

Yang, X., Pang, X., Xu, L., Fang, R., Huang, X., Guan, P., et al. (2009b). Accumulation of soluble sugars in peel at high temperature leads to stay-green ripe banana fruit. J. Exp. Bot. 60, 4051-4062. doi: 10.1093/jxb/erp238

Yu, G., Duan, J., Yan, H., Song, B., and He, Z. (2011). cDNA-AFLP analysis of gene expression differences between the flower bud and sprout-shoot apical meristem of Angelica sinensis (Oliv.) Diels. Genet. Mol. Biol. 34, 274-279. doi: $10.1590 /$ S1415-47572011000200018

Conflict of Interest Statement: The authors declare that the research was conducted in the absence of any commercial or financial relationships that could be construed as a potential conflict of interest.

Copyright (c) 2015 Wang, Tian, Shah, Pan, Diao and Gong. This is an open-access article distributed under the terms of the Creative Commons Attribution License (CC $B Y)$. The use, distribution or reproduction in other forums is permitted, provided the original author(s) or licensor are credited and that the original publication in this journal is cited, in accordance with accepted academic practice. No use, distribution or reproduction is permitted which does not comply with these terms. 